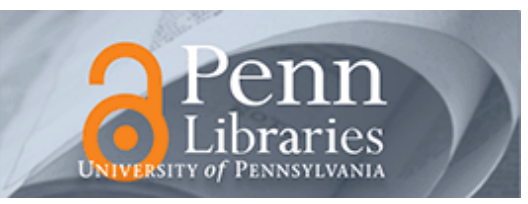

University of Pennsylvania ScholarlyCommons

June 2004

\title{
Public Shelter Admission among Young Adults with Child Welfare Histories by Type of Service and Type of Exit
}

Jung Min Park

University of Pennsylvania

Stephen Metraux

University of the Sciences in Philadelphia, s.metrau@usip.edu

Gabriel Brodbar

New York City Administration for Children's Services

Dennis P. Culhane

University of Pennsy/vania, culhane@upenn.edu

Follow this and additional works at: https://repository.upenn.edu/penniur_papers

Park, Jung Min; Metraux, Stephen; Brodbar, Gabriel; and Culhane, Dennis P., "Public Shelter Admission among Young Adults with Child Welfare Histories by Type of Service and Type of Exit" (2004). Penn IUR Publications. 7.

https://repository.upenn.edu/penniur_papers/7

Copyright The University of Chicago Press. Reprinted from Social Service Review, Volume 78, June 2004, pages 284-303.

This paper is posted at ScholarlyCommons. https://repository.upenn.edu/penniur_papers/7

For more information, please contact repository@pobox.upenn.edu. 


\title{
Public Shelter Admission among Young Adults with Child Welfare Histories by Type of Service and Type of Exit
}

\author{
Abstract \\ This study examines the prevalence and associated factors of New York City public shelter use among \\ young adults with histories of out-of-home care or nonplacement preventive services as teenagers. The \\ study finds that 19 percent of former child welfare service users entered public shelters within 10 years of \\ exit from child welfare. Persons with out-of-home placement histories are twice as likely to enter public \\ shelters (22 percent) as those who received nonplacement preventive services only (11 percent). Persons \\ exiting child welfare through absconding from child welfare have the highest rate of shelter use, followed \\ by those discharged to independent living.
}

\section{Comments}

Copyright The University of Chicago Press. Reprinted from Social Service Review, Volume 78, June 2004, pages 284-303. 


\title{
Public Shelter Admission
} among Young Adults with Child Welfare Histories by Type of Service and Type of Exit

Jung Min Park

University of Pennsylvania

Stephen Metraux

University of the Sciences in Philadelphia

Gabriel Brodbar

New York City Administration for Children's Services

Dennis P. Culhane

University of Pennsylvania

\begin{abstract}
This study examines the prevalence and associated factors of New York City public shelter use among young adults with histories of out-of-home care or nonplacement preventive services as teenagers. The study finds that 19 percent of former child welfare service users entered public shelters within 10 years of exit from child welfare. Persons with out-ofhome placement histories are twice as likely to enter public shelters (22 percent) as those who received nonplacement preventive services only (11 percent). Persons exiting child welfare through absconding from child welfare have the highest rate of shelter use, followed by those discharged to independent living.
\end{abstract}

The status and well-being of children who leave the child welfare system

Social Service Review (June 2004)

(C) 2004 by The University of Chicago. All rights reserved.

$0037-7961 / 2004 / 7802-0005 \$ 10.00$ 
are of increasing concern to researchers and policy makers (McDonald et al. 1996; Barth and Jonson-Reid 2000; Courtney 2000; Poertner, McDonald, and Murray 2000). Although a 2-decade-long series of federal legislation provides funding for programs that support children in their transition from foster care to self-sufficiency (Collins 2001), young people making this transition continue to have poor prospects for successful adult living (U.S. General Accounting Office 1999).

Research on the long-term outcomes of individuals who experienced child welfare services focuses primarily on educational attainment, employment status, public assistance receipt, substance use, criminal behaviors, and health (Buehler et al. 2000). Relatively few studies examine these individuals' adulthood experiences of homelessness. The existing studies of this phenomenon concentrate on individuals with a history of placement in out-of-home care, even though such children represent only 20-25 percent of all of those who receive child welfare services as a result of investigations of child abuse or neglect (Barth and JonsonReid 2000).

This study prospectively follows an extended cohort in New York City who, as older children, received child welfare services, and it examines the prevalence of their subsequent homeless shelter use. This study differentiates between children who were placed in out-of-home care and those who received preventive services without out-of-home placement. It further examines whether the risk of homeless shelter use varies by type of exit from the child welfare system.

\section{Background}

Table 1 summarizes prior research on intersections between histories of child welfare services and adult homelessness. Most previous studies examine the rates of prior out-of-home placement among people who were homeless at the time of study; far less research examines rates of homelessness among people with histories of child welfare involvement. The work by Irving Piliavin and colleagues (1993) draws attention to the high prevalence of childhood out-of-home placements among adult homeless populations, finding that 39 percent of homeless subjects reported a history of placement in out-of-home care. Several subsequent studies report consistent findings. The most comprehensive consistent results are reported by Martha Burt and associates (1999) in their national survey of the homeless population. In a study that utilizes nonhomeless comparison groups, Ellen Bassuk and associates (1997) find an elevated risk of family homelessness among mothers who experienced out-of-home placements as children.

Although adults who had out-of-home placements are widely considered to be at higher risk for subsequent homelessness (Stoner 1999; Barth and Jonson-Reid 2000; Collins 2001), far fewer studies examine 
Table 1

Selected Previous Studies of Homelessness and Childhood Out-of-Home Placement (Listed Chronologically by Date of Publication)

\begin{tabular}{|c|c|c|c|c|c|c|}
\hline Study & $\begin{array}{l}\text { Type of } \\
\text { Study }\end{array}$ & $\begin{array}{l}\text { Data Collec- } \\
\text { tion Date }\end{array}$ & Data Collection Method & Target Population & Sample Size $(N)$ & Key Findings \\
\hline \multicolumn{7}{|l|}{$\begin{array}{l}\text { Homelessness among peo- } \\
\text { ple with child welfare } \\
\text { histories: }\end{array}$} \\
\hline Courtney et al. (2001) & $\mathrm{L}$ & 1998 & $\begin{array}{l}\text { In-person interviews } \\
\text { mainly; Wisconsin }\end{array}$ & $\begin{array}{l}\text { Youths who exited out-of- } \\
\text { home care }\end{array}$ & 113 & $\begin{array}{l}12 \% \text { of youths exiting out-of-home } \\
\text { care experienced homelessness in } \\
\text { the first } 12-18 \text { months following } \\
\text { exit }\end{array}$ \\
\hline $\begin{array}{l}\text { Benedict, Zuravin, and } \\
\text { Stallings (1996) }\end{array}$ & $\mathrm{L}$ & 1993-94 & $\begin{array}{l}\text { In-person interviews; } \\
\text { Baltimore }\end{array}$ & $\begin{array}{l}\text { Adults who were in out-of- } \\
\text { home care as children }\end{array}$ & 214 & $\begin{array}{l}27 \% \text { were ever homeless at some } \\
\text { time in the past }\end{array}$ \\
\hline Cook (1994) & C & 1991 & $\begin{array}{l}\text { Telephone and in-person } \\
\text { interview; eight states }\end{array}$ & Former foster youths & 810 & $\begin{array}{l}25 \% \text { of the youths were homeless at } \\
\text { least one night over the } 2.5-4 \\
\text { years following discharge from } \\
\text { foster care }\end{array}$ \\
\hline Barth (1990) & $\mathrm{C}$ & 1988 & $\begin{array}{l}\text { In-person interview; San } \\
\text { Francisco Bay Area, } \\
\text { California }\end{array}$ & Former foster youths & 55 & $\begin{array}{l}35 \% \text { had been homeless or experi- } \\
\text { enced very frequent living ar- } \\
\text { rangements change }\end{array}$ \\
\hline \multicolumn{7}{|l|}{$\begin{array}{l}\text { Child welfare histories } \\
\text { among current home- } \\
\text { less individuals: }\end{array}$} \\
\hline Burt et al. (1999) & $\mathrm{C}$ & $1995-96$ & $\begin{array}{l}\text { Telephone and mail sur- } \\
\text { vey; United States }\end{array}$ & $\begin{array}{l}\text { Homeless assistance pro- } \\
\text { viders and service users }\end{array}$ & 4,207 & $\begin{array}{l}27 \% \text { of homeless clients lived in fos- } \\
\text { ter care, a group home, or other } \\
\text { institutional setting during } \\
\text { childhood }\end{array}$ \\
\hline
\end{tabular}




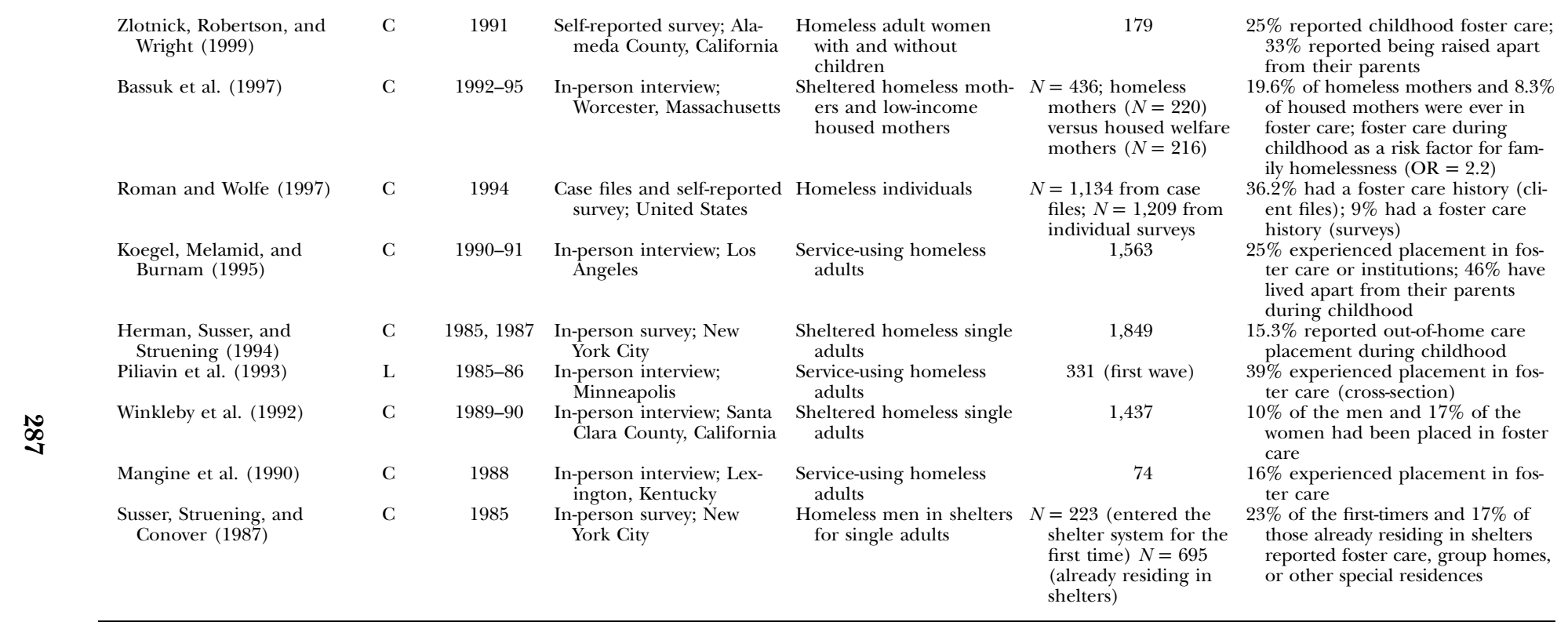

Note. $-\mathrm{L}=$ longitudinal interviews; $\mathrm{C}=$ cross-sectional interviews; $\mathrm{OR}=$ odds ratio. 
rates of homelessness among people with childhood histories of involvement with child welfare services. A small number of studies indicate rates of homelessness in the range of 12-35 percent among this group (Barth 1990; Cook 1994; Benedict et al. 1996; Courtney et al. 2001).

There are two primary explanations for why children in out-of-home care are vulnerable to homelessness. Both of these may be particularly important for young adults who exit care. First, young adults who exit out-of-home placements are poorly prepared for independent living (Mallon 1998). Majorities of them leave their placements without a job or high school diploma and make living arrangements with relatives after leaving their placements (Cook 1994; Mech 1994; Lindsey and Ahmed 1999; McMillen and Tucker 1999). Educational and economic disadvantages continue after exit from out-of-home care and into adulthood (Buehler et al. 2000). So, too, the living arrangements made on leaving out-of-home care are typically unplanned and, if the subject is living with family, are likely to be unstable because many of these youths were removed from these homes only a few years earlier (McMillen and Tucker 1999).

Second, the experiences borne by this group, both in their families of origin and while in the child welfare system, may leave them more prone to psychosocial problems that impede their ability to secure and maintain stable housing. In adult life, compared with the more general population, individuals who left out-of-home care are more prone to difficulties in marriage and family life, substance abuse, and mental health problems (Buehler et al. 2000). While the vast majority of children receiving out-of-home placements exit them before age 17 (Courtney and Barth 1996; McMillen and Tucker 1999), most of those who exit care in their late teens and beyond enter out-of-home care as teenagers and comprise "the most troubled of all children in out-of-home care" (McMillen and Tucker 1999, p. 341).

Although there is widespread agreement that childhood out-of-home care is associated with a subsequent vulnerability to homelessness, the paucity of empirical findings on this topic is part of a more general dearth of research on adult outcomes of children after out-of-home care (Mech 1994; McDonald et al. 1996; McMillen and Tucker 1999; Courtney et al. 2001). Samples of people with prior child welfare involvement are inherently difficult to recruit. Furthermore, the extant studies with findings on childhood out-of-home placement and homelessness contain such methodological weaknesses as small numbers of subjects and reliance on retrospective self-reports, which can be faulty when recalled events occurred over a long period of time. The findings on homelessness are limited to reports of prevalence of homelessness over a particular time period. This provides parameters for the extent of the association but fails to provide more in-depth analyses that yield insights on the nature of this association. The studies do not specifically focus on 
those who were in the child welfare system as they approached adulthood. Finally, most of the existing studies on the relationship between child welfare histories and homelessness focus exclusively on individuals with childhood experience in out-of-home care and do not include comparison groups in their analyses.

Our study adds to the literature by focusing on rates of adult homelessness among persons leaving out-of-home care. It provides a relevant point of comparison by looking at the same outcomes for persons who exited the child welfare system but were not in out-of-home placement. To do so, the study matches two large administrative data sets from New York City, one containing child welfare records and the other containing records of homeless shelter use. It is thus possible to follow a cohort of children into adulthood and to ascertain adult shelter use among this group. The use of multivariate regression also allows assessment of the comparative risks for incurring shelter stays associated with the different child welfare services: nonplacement preventive services versus out-ofhome placement situations. It is also possible to assess variations by types of exit, including exits from nonplacement preventive services, exits from out-of-home care to family reunification, exits to independent living, and exits by absconding (i.e., running away).

\section{Method}

\section{Data and Sample}

The data for the present study are drawn from the Child Care Review Service maintained by the New York City Administration for Children's Services (ACS), and from administrative data of the New York City Department of Homeless Services (DHS). The Child Care Review Service is a computer database that contains information about children receiving ACS services. It includes such details as service and discharge dates, movements in foster care, the reason for discharge, permanency planning goals, and demographic characteristics, as well as identifiers such as name, date of birth, and Social Security number. Data are available from 1981 to 2001. Since 1986, DHS has tracked public shelter use through the databases covering its family shelter system and its single adult shelter system; DHS data are available through 2001. Both DHS databases include information on identifiers, basic demographic characteristics, entries, exits, and subsequent readmission. Observations across the ACS and DHS data sets are considered to match if one of two criteria were met. Both observations must have a matching Social Security number and matching first name, last name, or date of birth. In the absence of matching Social Security numbers, the sex, date of birth, and first and last names must all match.

This study follows individuals who were involved with ACS as children. 
Three criteria determine inclusion into the study group. First, to be eligible, an individual must have a record of out-of-home placement in the ACS system or nonplacement preventive services administered by ACS. Second, the individual's final discharge or case closure from the ACS system must have been recorded sometime between 1988 and 1992. These inclusion dates ensure continuity between DHS and ACS systems. They also permit the tracking of each individual in the DHS system for a period of at least 9 and up to 10 years. Third, persons selected for the study group must have been at least age 16 at the time of discharge or case closure. This permits us to follow them as they enter into adulthood, although not all of them were eligible to stay in DHS shelters immediately on their entry into this risk set. New York City Department of Homeless Services family shelters provide shelter to females age 16 and over who enter with children. Although it is lower than the minimum age, DHS single adult shelters admit some persons under the age of 21. Finally, records of included individuals must list one of the following reasons for exit from the ACS system: a return to a natural parent, a release to a relative or primary resource person, a release to their own responsibility, adulthood attained, absconding, or preventive services not needed.

This list of exit types excludes those because of death, moving out of district, case incorrect, military enlistment, mental institutionalization, correctional institutionalization, adoption, and administrative action. The above exit categories are excluded because of their small proportions, subjects' ineligibility for the public shelter system in New York City, and a lack of clarity regarding subjects' destinations on exit. Of 16,835 children who met other inclusion criteria, 4,877 (29 percent) are classified into the above categories and thus excluded from the study, yielding a study group of 11,958 persons. Since the current study concerns those exiting the child welfare system as teenagers only, the study group may not be comparable with previous studies of homelessness.

\section{Variables}

The dependent variable for this study is first-time admission to a DHS shelter. These shelters fall into one of two systems: the first is for unaccompanied adults; the second is for adults accompanied by children and women who are pregnant. Using the DHS data, table 2 shows that the demographic characteristics of adults in the two systems are very different, reflecting differences between homeless males and females in their relationships to family. Those in the family system were almost three-fourths female and had a median age of 29, while those in the single adult system were over three-fourths male and had a median age of 39. These demographic differences suggest that there are differences in the dynamics that lead to stays in each of these two shelter systems. 
Table 2

Adults Who Stayed in New York City Department of Homeless Services SHELTERS IN 1998

\begin{tabular}{lrrr}
\hline System & Male & \multicolumn{1}{c}{ Female } & Median Age \\
\hline Single adult & $18,901(79.9)$ & $4,769(21.1)$ & 39.4 \\
Family & $4,863(26.5)$ & $13,486(73.5)$ & 28.8 \\
\cline { 2 - 4 } Total & $23,764(56.6)$ & $18,255(43.4)$ & 35.2 \\
\hline
\end{tabular}

Note. - Results were calculated by the authors using data from the New York City Department of Homeless Services. Numbers in parentheses are percentages.

In order to consider the nature of these differences, the overall risk for a DHS shelter stay is also parsed into competing risks of family shelter stay and single adult shelter stay.

The independent variables include demographic and child welfarerelated variables. The demographic variables include indicators of race or ethnicity, gender, and age. Race or ethnicity are classified as NonHispanic African American, Hispanic, Non-Hispanic Caucasian and other, or unknown. The child welfare-related variables include the length of stay in the child welfare system, age at final exit from child welfare, an indicator for a history of out-of-home placement, year of ACS case closure, and the type of final exit from child welfare. Type of final exit is classified into four categories: children exiting ACS out-ofhome care to independent living on attaining adulthood; children exiting ACS out-of-home care to a reunification with parents, other relatives, or primary resource persons; children absconding from ACS out-of-home care; and children exiting the ACS system while receiving nonplacement preventive services. The first three categories involve an experience of out-of-home placement. The final category may follow a period of out-of-home placement, but it usually does not. One other variable is an indicator of whether the individuals in the study group were in DHS family shelters as children. Table 3 shows means and percentages for these variables.

\section{Data Analysis}

Descriptive analyses are conducted to produce the information on the study group's background characteristics and the extent of public shelter use. Hazard functions for shelter admission are also estimated by experience of out-of-home placement and by the type of exit. The hazard function quantifies the instantaneous risk that an event will occur during a specific interval, given that the event has not already occurred (Allison 1995).

Cox regression analysis, a proportional hazards model that uses partial 
Table 3

Description of the Study Group

\begin{tabular}{lr}
\hline Measure & $\%$ \\
\hline Race and ethnicity: & \\
African American (non-Hispanic) & 45.2 \\
Hispanic & 24.8 \\
Caucasian and other (non-Hispanic) & 12.2 \\
Unknown & 17.8 \\
Gender: & \\
Female & 53.9 \\
Male & 46.1 \\
Year of final exit from child welfare: & 15.2 \\
1988 & 17.0 \\
1989 & 19.5 \\
1990 & 23.5 \\
1991 & 24.9 \\
1992 & 29.1 \\
Age in 2001 (mean) & 17.8 \\
Time at final exit from child welfare (mean) & 1.8 \\
Ever out-of-home placement & 67.9 \\
Type of final exit from child welfare: & \\
Exit from out-of-home care to reunification & 31.5 \\
Exit from out-of-home care to independent living & 25.0 \\
Absconding from out-of-home placement & 3.8 \\
Exit from preventive services & 11,958 \\
\hline &
\end{tabular}

likelihood estimation, examines the impact of the selected variables on the risk of public shelter admission. Cox regression allows for adjustments that take into account periods of time in which an individual is not at risk of an event and produces approximately unbiased estimates of the effects of explanatory variables on the hazard rates for experiencing an event of interest (Allison 1995). The model assumes that the hazard of public shelter use for individual $i$ at time $t, h_{i}(t)$, is given by the following:

$$
\mathrm{h}_{\mathrm{i}}(t)=\lambda_{0}(t) \exp \left\{\beta x_{i}\right\},
$$

where $\lambda_{0}(t)$ is an unspecified baseline hazard function, $\beta$ is the vector of parameter coefficients of covariates, and $x_{i}$ is a vector of coefficients for individual $i$. In the model, the event is public shelter admission after final exit from the child welfare system. In another set of equations, entry into family and single adult shelters are modeled as competing risks. Here the models are estimated separately for each event type, with no loss of statistical precision (Allison 1995). Repeat admission to the shelter system is not considered an event, because this study focuses only on first admissions to the public shelter system.

Individuals from the same family tend to be more alike than randomly 
Table 4

Rates of DHS Shelter Use by Selected Characteristics

\begin{tabular}{lccc}
\hline & $\begin{array}{c}\text { Either Shelter } \\
\text { System* } \\
(\%)\end{array}$ & $\begin{array}{c}\text { Family Shelter } \\
\text { System } \\
(\%)\end{array}$ & $\begin{array}{c}\text { Single Adult } \\
\text { Shelter System } \\
(\%)\end{array}$ \\
\hline History of out-of-home care: & & & \\
$\quad$ Yes & 22.4 & 17.0 & 8.9 \\
$\quad$ No & 10.8 & 9.4 & 2.5 \\
Type of final exit from ACS: & 19.4 & 14.7 & 7.6 \\
$\quad$ Reunification & 25.6 & 18.8 & 10.7 \\
Independent living & 33.6 & 22.4 & 15.6 \\
Absconding from care & 12.4 & 11.0 & 3.0 \\
$\quad$ Preventive services & & & 8.9 \\
Race and ethnicity: & 24.3 & 18.8 & 5.2 \\
African American (non- & 14.1 & 11.0 & 3.0 \\
$\quad$ Hispanic) & 6.0 & 4.0 & 4.8 \\
Hispanic & & 23.7 & 9.3 \\
Caucasian (non-Hispanic) & 25.1 & 3.8 & 6.9 \\
Gender: & 11.1 & 14.5 & \\
Female & 18.7 & & \\
Male & & & \\
Total & & & \\
\hline
\end{tabular}

NotE. - DHS = Department of Homeless Services; ACS = the New York City Administration for Children's Services. All relationships are statistically significant for $\chi^{2}$ test $(p<.001)$.

* "Either shelter system" category reflects the unduplicated sum of the other two columns.

chosen individuals. Failure to consider such dependencies among observations can lead to biased standard error estimates and inflated test statistics. Since sibling groups represent 28 percent of these data, this study checks for potential bias resulting from the presence of sibling groups. It applies the WLW method for getting robust variance estimates that allow for correlation in event times among individuals (Wei, Lin, and Weissfeld 1989; Allison 1995).

\section{Results}

Prevalence and Patterns of Adult Public Shelter Use after Exit from Child Welfare

Table 4 displays rates of public shelter use during the 10-year period following exit from the ACS system. Overall, 19 percent of the study group experienced a stay in public shelters. Breaking this overall rate down shows that the rate of public shelter use is two times higher for persons who experienced out-of-home placement, as compared with those who received preventive services only (22 vs. 11 percent). The rate of public shelter use also varies substantially across the type of final exit, with the runaway subgroup having the highest rate (34 percent) 


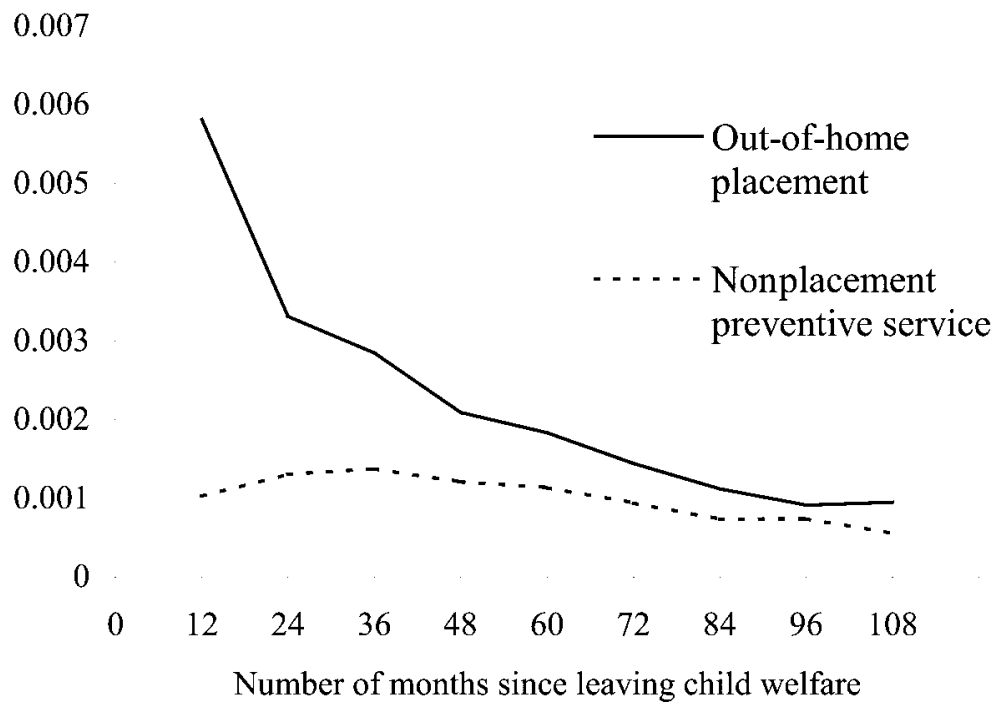

FIG. 1.-Hazard functions of public shelter use by histories of out-of-home placement

and the subgroup exiting from preventive services having the lowest rate (12 percent). Among the demographic categories, Non-Hispanic African Americans are the only racial or ethnic group for which the rate (24 percent) is higher than the overall rate, and substantial differences exist between genders, with females experiencing shelter stays at over twice the rate of males ( 25 vs. 11 percent). This gender difference also carries over to disparities between the two shelter systems. Persons in the study group experienced a shelter stay in the family system at over twice the rate ( 15 percent) that they experienced stays in the single adult system (7 percent). Females who stayed in a shelter did so predominantly in family shelters. Males who stayed in shelters in fewer numbers stayed mostly in single adult shelters.

Figures 1 and 2 show hazard functions over time by the presence of out-of-home placement experience and type of ACS exit, respectively. Figure 1 shows that the hazard of public shelter use for those with histories of out-of-home placement is highest during the first $11 / 2$ years after exiting ACS services and then declines steadily. By contrast, the hazard of public shelter use for those who only received nonplacement preventive services remains comparatively stable over time.

In figure 2, the risk of entering a public shelter is highest for the runaway group over the entire observation period and is lowest for those leaving care while receiving preventive services. The hazard rates are very similar for those discharged to either independent living or reunification, and both decrease steadily over time. The hazard rates for 


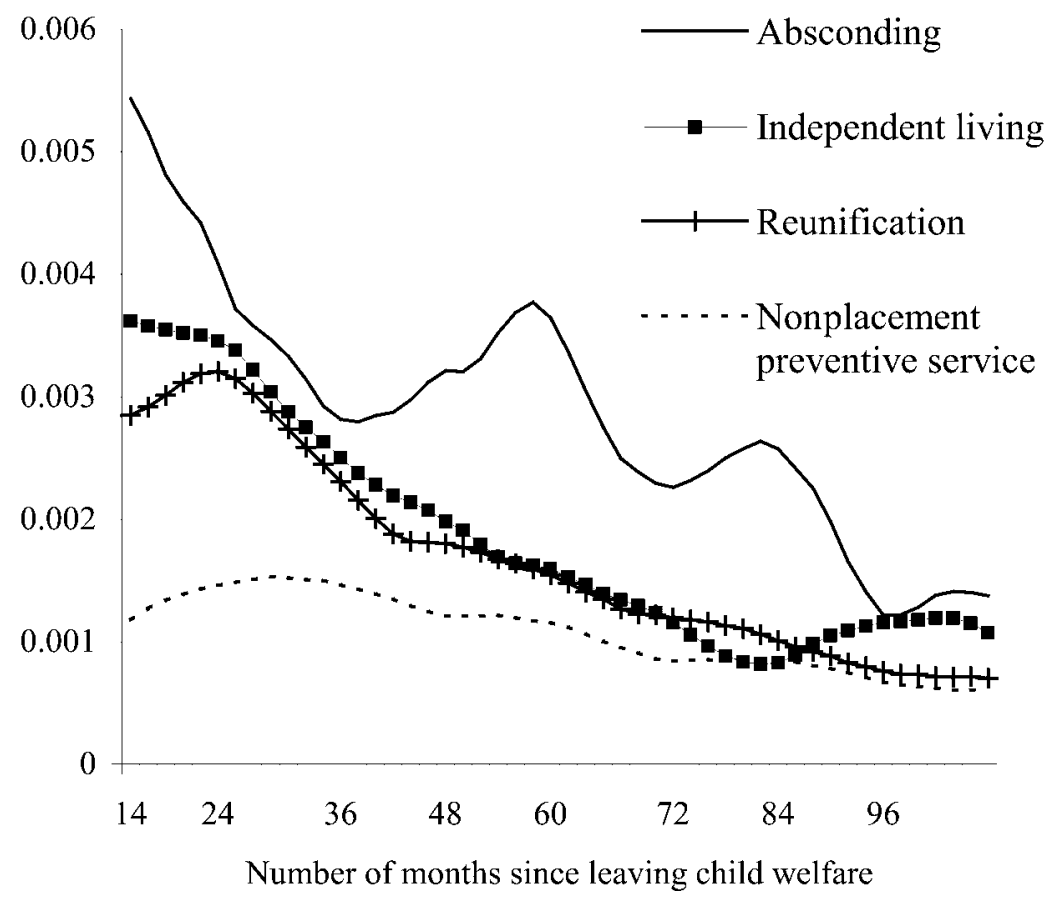

FIG. 2.-Hazard functions of public shelter use by type of final exit from child welfare

all four groups roughly converge once those in the study group were 8 years into the risk period.

\section{Factors Associated with the Risk of Public Shelter Use}

Table 5 contains the results from Cox regression models for public shelter use after leaving child welfare services. Model 1 shows the results of Cox regression for the entire study group. After controlling for significant differences among race or ethnicity, gender, and year of exit, several ACS-related covariates remain statistically significant for increased risk of public shelter use in adulthood. The risk of public shelter use for those with a history of out-of-home placement is 1.7 times the risk for those who did not receive an out-of-home placement. Those who left the child welfare system as runaways are 1.8 times more at risk for staying in public shelters than those leaving child welfare while receiving preventive services. Each year of increase in age of exit is associated with an additional 31 percent increase in the risk for shelter use. Also noteworthy is that, after controlling for the other factors, neither discharge to reunification nor discharge to independent living shows statistically significantly different risks from the reference category. 
Table 5

Risk Ratios in the Cox Proportional Hazards Models of Public Shelter Use

\begin{tabular}{|c|c|c|c|}
\hline & \multirow[b]{2}{*}{$\begin{array}{l}\text { Model } 1 \\
\quad(\text { Total })\end{array}$} & \multicolumn{2}{|c|}{$\begin{array}{c}\text { Model } 2 \\
\text { (Competing Risk Model) }\end{array}$} \\
\hline & & $\begin{array}{c}\text { Family } \\
\text { Shelter System }\end{array}$ & $\begin{array}{l}\text { Single Adult } \\
\text { Shelter System }\end{array}$ \\
\hline History of out-of-home care & $1.67 * * *$ & $1.51 * * *$ & $2.27 * * *$ \\
\hline \multicolumn{4}{|l|}{ Type of final exit from ACS: } \\
\hline Reunification & 1.03 & .95 & 1.29 \\
\hline Independent living & 1.05 & 1.07 & 1.07 \\
\hline Absconding & $1.78^{* * * *}$ & $1.42 * * *$ & $2.90 * * *$ \\
\hline Age at final exit from ACS & $1.31 * * *$ & $1.19 * * *$ & $1.63 * * *$ \\
\hline Length of stay in ACS & .98 & $.98^{*}$ & .96 \\
\hline Childhood shelter use & 1.25 & 1.13 & $1.63^{*}$ \\
\hline \multicolumn{4}{|l|}{ Race and ethnicity: } \\
\hline African American & $3.87 * * *$ & $4.22 * * *$ & $3.40 * * *$ \\
\hline Hispanic & $2.35^{* * * *}$ & $2.47 * * *$ & $2.22 * * *$ \\
\hline \multicolumn{4}{|l|}{ Unknown race or } \\
\hline ethnicity & $3.21 * * *$ & $3.58 * * *$ & $2.62 * * *$ \\
\hline Female & $2.45^{* * * *}$ & $7.46^{* * * *}$ & $.49 * * *$ \\
\hline Exit in 1988 & $1.58^{* * * *}$ & $1.25^{*}$ & $2.73 * * *$ \\
\hline Exit in 1989 & $1.29 * * *$ & 1.09 & $2.03 * * *$ \\
\hline Exit in 1990 & 1.12 & 1.05 & $1.38^{*}$ \\
\hline Exit in 1991 & .96 & .97 & .95 \\
\hline \multicolumn{4}{|l|}{ Likelihood ratio $\chi^{2}$} \\
\hline$(\mathrm{df}=15)$ & 1,290 & 1,436 & 673 \\
\hline
\end{tabular}

Note. $-N=11,958$. ACS $=$ the New York City Administration for Children's Services $* p<.05$.

$* * * \quad p<.001$.

Table 5 also features a second Cox regression model that casts stays in family shelters and stays in single adult shelters as competing risks. Two different profiles emerge, centering around the gender difference in shelter utilization. Compared with males, females are 7.5 times more likely to enter family shelters but only 0.5 times as likely to enter single adult shelters. A history of out-of-home care, absconding from out-ofhome care, and age at ACS exit are all associated with a significantly increased risk for both types of shelter stay, but the magnitudes of risk associated with the covariates are greater for single adult shelter stays. Again, neither discharge to independent living nor reunification produces coefficients that are statistically significantly different from the reference category. Finally, childhood homeless experience increases the risk for shelter use, but only in single adult shelters.

To ensure that the differences in the coefficients are not the result of random variation, our study uses likelihood-ratio $\chi^{2}$ statistics to test the null hypothesis that all coefficients are the same across the two events. The $\chi^{2}$ of 819 with 15 degrees of freedom generates a highly statistically significant $p$-value, thus ruling out the possibility that all coefficients are equal. The Cox regression models in table 5 are also 
fitted for two subgroups, those with a history of out-of-home placement and those receiving only preventive services (results not shown). The results differ little across the two subgroups and are similar to the first model presented in table 5. Using robust variance estimates produces almost identical parameter estimates and statistical significance as does using the partial likelihood method. This suggests that the presence of siblings in the study group does not substantially bias the results.

\section{Discussion}

This study follows 11,958 young adults who exited the child welfare system in New York City at age 16 or older and examines the prevalence of public shelter use in the 10-year period after their exit. Overall, 19 percent of this group experienced a public shelter stay during this time period. A history of out-of-home care, age at exiting the child welfare system, and gender are among the covariates strongly associated with an increased risk for shelter stay. These prevalence rates and attendant dynamics carry implications for understanding the nature of the relationship between child welfare and shelter use, as well as for policy interventions in this area.

This is the largest study to date of the prevalence of homelessness among those who received child welfare services. The findings of this study further support the conclusion of prior research that homelessness is not an unusual experience among those with child-welfare service experience.

The results show that any childhood experience of out-of-home care contributes to a high risk of shelter use as an adult. Twenty-two percent of those who experienced out-of-home care as children had a shelter stay during the risk period. By comparison, shelter stays are found among 11 percent of those who had nonplacement preventive services. After controlling for the overall presence of out-of-home care, the results indicate that whether the person aged out of out-of-home care directly into adulthood did not significantly contribute to this risk. This would suggest that adult shelter use is not so much due to the failure of outof-home care facilities to prepare for adult living, as to factors linked with the more general out-of-home care experience. Such factors might include lasting effects of the abuse or neglect that necessitated such a placement, the lingering effects of removal from one's home, the decreased family support stemming from such situations, and stressful events like chronic poverty. It must again be emphasized that such conclusions are tentative and serve primarily to offer directions for future research.

Older age at time of exit from the ACS system is associated with a higher risk for shelter use, especially for shelter use in single adult shelters. This is in part attributable to the different risk period among 
individuals in the study group, as single adult shelters accept relatively few people under age 21. If youths under age 21 are not accompanied by children, they are generally referred to the youth shelter system. Youths exiting ACS at age 16 have a shorter risk period for entering the single adult shelter system, compared with those doing so at age 18 . This is because all individuals in this study are observed for the same period of 10 years. An alternative explanation consistent with findings by J. Curtis McMillen and Jayne Tucker (1999) identifies these older children leaving child welfare as a group that has psychosocial problems. These problems impede efforts to maintain stable living arrangements in adulthood. More research is needed on this issue.

The finding that minorities in the study group are at higher risk for homelessness is not surprising. Minorities, and especially African Americans, are disproportionately represented among the homeless population (Blasi 1994; Burt et al. 1999; Culhane and Metraux 1999). This generally higher risk for homelessness is usually regarded as indicative of the higher rates of poverty and reduced familial resources associated with long-term poverty among African Americans (Burt et al. 1999; Culhane and Metraux 1999). Also not surprising is the finding that the risk of shelter use is higher for those leaving care by running away than for those experiencing other types of exits from the child welfare system. About one in three persons who left out-of-home care as runaways subsequently spend time in a public shelter. Runaway youth are at high risk for experiencing social adjustment difficulties, including poor academic performance, deviant behaviors, and inadequate health care (Whitbeck and Simons 1990; Fasulo et al. 2002). They also appear to be difficult to engage in services that could prevent adult homelessness.

The prevalence of shelter use enables a conservative assessment of the prevalence of overall homelessness and is more likely to underestimate homelessness among the males in the study group than among the females. This accounts for at least part of the disparity suggested by findings that 25 percent of the young women leaving ACS care experienced a shelter episode in the following 10 years, as compared with 11 percent of their male counterparts. The results also point to substantial differences in how homelessness is experienced among the genders in the study group, as 94 percent of the women who experienced shelter stays did so in family shelters, while only 34 percent of the men did so.

These differences in the types and frequency of shelter use are consistent with characteristics found in the overall homeless population, both nationwide and in New York City. According to prior research (Metraux and Culhane 1999), women are at highest risk for shelter use in their mid-twenties, and most women become homeless as part of a family-most often as single head of a family with preschool-age children. Men, by contrast, comprise the majority of the adults who are 
homeless without their children, and, at present, they are at highest risk for shelter use in their thirties and forties. When men use shelters, they overwhelmingly use them as individuals, although many acknowledge having fathered children. Men, especially younger men, also are more likely than women to spend homeless episodes in circumstances, such as street locations or vacant buildings, that this study is unable to track (Burt and Cohen 1989; Rossi 1989; North and Smith 1993; Interagency Council on the Homelessness 1994; Culhane and Metraux 1999; Metraux and Culhane 1999).

It is notoriously difficult to assess the degree to which data on shelter use capture overall homelessness. Gauging homelessness in New York City on the basis of DHS shelter data is made even more difficult because of the presence of a network of privately operated shelters, which are not included in the DHS databases. The network comprises an estimated 15-20 percent of New York City's total shelter beds (Culhane et al. 1997; NYCDHS 2003). In order to obtain an accurate assessment of overall homelessness, it is also necessary to take into account another separate category of youth shelters that collectively provide another 429 emergency shelter beds, alongside DHS facilities and private shelters. A New York City Department of Homeless Services study (NYCDHS 2003) attempting to enumerate all homeless persons in Manhattan on a night in February 2003 finds that 56 percent of an estimated 7,222 homeless persons were in DHS shelters. Of the remainder, 25 percent were enumerated in unsheltered locations, and 19 percent stayed in other shelters, drop-in centers, and emergency rooms. Those using non-DHS shelters were younger than the sheltered homeless population and tended to be male.

But such a point-prevalent snapshot survey substantially understates the proportion of homeless persons who do use shelters over the course of a longitudinal study. Most persons will use a shelter for at least some part of the period they are homeless (Rossi 1989; Dennis 1993; Koegel, Burnam, and Morton 1996; Burt et al. 1999). This would be especially so in New York City, which has the most extensive shelter system of any U.S. city and a court-mandated charge to provide shelter to any family or individual adult claiming to be homeless (Culhane, Metraux, and Wachter 1999). Over the 10-year risk period, most people can be presumed to have utilized DHS shelters at some point, though on a given night they may be counted as homeless in nonshelter or private shelter arrangements. Those staying in youth shelters would be less likely to show up in nonshelter or private shelter counts. Finally, if someone in the study group were homeless subsequent to their time under ACS supervision or homeless in a jurisdiction outside of New York City, such an episode would also be missed, although research suggests low rates of intercity migration among the homeless population (Wolch, Rahimian, and Koegel 1993). 
The uncertainty surrounding these questions of coverage means that, although women in the study group are substantially more likely to use shelters in the 10-year period following an exit from child welfare services, one cannot rule out the possibility that men in the study group might become homeless at rates comparable with the women but use shelters substantially less. Also conceivable, based on dynamics of the general homeless population, is that men may be more successful in avoiding homelessness until later in adulthood. Thus, it is likely that if the risk period were extended for an additional 10 years, the gender differential in the prevalence of homelessness would diminish.

The presence of substantial proportions of women from the study group in shelters, many with their own children, creates both concern and an opportunity for intervention. Little is yet known about the effect of childhood homelessness on adult outcomes, but when women with child welfare services histories bring children into shelters, the possibility persists that their children are at greater risk of needing services from both ACS and DHS into their adulthood. By contrast, by extending services to adults who received its services as children, and particularly to those parenting their own children, ACS may have identified a means to provide a regimen of housing and supportive services that may obviate the need for DHS services among women whose families are at risk for homelessness.

Limitations of the study, in addition to those already discussed, include the unavailability of data on such areas as education, employment, behavioral disorders, and health problems. These factors can mediate the association between child welfare involvement and homelessness. In addition, further investigation is needed to examine the association between the type of out-of-home care, such as foster home and institutional care, and the likelihood of being homeless. This is important because there is evidence that children in group care are likely to have worse outcomes as young adults than children who were in regular foster homes (Susser et al. 1987; McDonald et al. 1996; Kerman, Wildfire, and Barth 2002). Furthermore, the study group comprises individuals who received child welfare services in New York City. Since child welfare systems vary across states and counties, this geographic limitation should be considered before the findings are generalized to other jurisdictions.

The current findings suggest that many children with a history of child welfare system involvement need continued supports after they leave the system in order to make a transition to stable adult living arrangements. Targeted housing subsidies bundled with education and employment assistance might provide such support. In 2001, ACS started using such an approach in developing over 200 new units of permanent supportive housing for current and former child welfare-involved families who are on track to exit ACS out-of-home care to adulthood. In addition, in cooperation with the New York City Housing Authority, ACS 
created and currently manages programs that greatly facilitate access to Section 8 vouchers for all qualified families in the child welfare system and for children aging out of ACS care. Services to strengthen family functioning may result in better outcomes for children discharged to reunification. Such approaches would be consistent with the findings of this study. Furthermore, the findings promise to be beneficial in designing evaluations of programs and in assessing their impact on homelessness among this target population.

\section{References}

Allison, Paul David. 1995. Survival Analysis Using the SAS System: A Practical Guide. Cary, N.C.: SAS Institute.

Barth, Richard P. 1990. "On Their Own: The Experiences of Youth after Foster Care." Child and Adolescent Social Work 7 (5): 419-40.

Barth, Richard P., and Melissa Jonson-Reid. 2000. "Outcomes after Child Welfare Services: Implications for the Design of Performance Measures." Children and Youth Services Review 22 (9): 763-87.

Bassuk, Ellen L., John C. Buckner, Linda F. Weinreb, Angela Browne, Shari S. Bassuk, Ree Dawson, and Jennifer N. Perloff. 1997. "Homelessness in Female-Headed Families: Childhood and Adult Risk and Protective Factors." American Journal of Public Health 87 (2): 241-48.

Benedict, Mary I., Susan Zuravin, and Rebecca Y. Stallings. 1996. "Adult Functioning of Children Who Lived in Kin versus Nonrelative Family Foster Homes." Child Welfare 75 (5): 529-49

Blasi, Gary. 1994. "And We Are Not Seen: Ideological and Political Barriers to Understanding Homelessness.” American Behavioral Scientist 37 (4): 563-86.

Buehler, Cheryl, John G. Orme, James Post, and David A. Patterson. 2000. "The LongTerm Correlates of Family Foster Care." Children and Youth Services Review 22 (8): $595-625$.

Burt, Martha R., Laudan Y. Aron, Toby Douglas, Jesse Valente, Edgar Lee, and Britta Iwen. 1999. Homelessness: Programs and the People They Serve; Findings of the National Survey of Homeless Assistance Providers and Clients: Summary. Washington, D.C.: Urban Institute Press.

Burt, Martha R., and Barbara E. Cohen. 1989. "Differences among Homeless Single Women, Women with Children, and Single Men.” Social Problems 36 (5): 508-24.

Collins, Mary Elizabeth. 2001. "Transition to Adulthood for Vulnerable Youths: A Review of Research and Implications for Policy.” Social Service Review 75 (2): 271-91.

Cook, Ronna J. 1994. "Are We Helping Foster Care Youth Prepare for Their Future?" Children and Youth Services Review 16 (3-4): 213-29.

Courtney, Mark E. 2000. "Research Needed to Improve the Prospects for Children in Outof-Home Placement." Children and Youth Services Review 22 (9): 743-61.

Courtney, Mark E., and Richard P. Barth. 1996. "Pathways of Older Adolescents out of Foster Care: Implications for Independent Living Services." Social Work 41 (1): 75-83.

Courtney, Mark E., Irving Piliavin, Andrew Grogan-Kaylor, and Ande Nesmith. 2001. "Foster Youth Transitions to Adulthood: A Longitudinal View of Youth Leaving Care." Child Welfare 80 (6): $685-717$.

Culhane, Dennis P., Edmund F. Dejowski, Julie Ibanez, Elizabeth Needham, and Irene Macchia. 1997. "Public Shelter Admission Rates in Philadelphia and New York City: The Implications of Turnover for Sheltered Population Counts." Pp. 101-34 in Understanding Homelessness: New Policy and Research Perspectives, edited by Dennis P. Culhane and Steven P. Hornburg. Washington, D.C.: Fannie Mae Foundation.

Culhane, Dennis P., and Stephen Metraux. 1999. "One-Year Rates of Public Shelter Utilization by Race/Ethnicity, Age, Sex and Poverty Status in New York City (1990 and 1995) and Philadelphia (1995)." Population Research and Policy Review 18 (3): 219-36.

Culhane, Dennis P., Stephen Metraux, and Susan M. Wachter. 1999. "Homelessness and 
Public Shelter Provision in New York City." Pp. 203-32 in Housing and Community Development in New York City: Facing the Future, edited by Michael Schill. Albany, N.Y.: SUNY Press.

Dennis, Michael L. 1993. "Coverage of a Service-Based Methodology: Findings from the DC*MADS Homelessness Study." Paper presented at "Towards Census 2000: Research Issues for Improving Coverage of the Homeless Population," Arlington, Va., September.

Fasulo, Samuel J., Theodore P. Cross, Peggy Mosley, and Joseph Leavey. 2002. “Adolescent Runaway Behavior in Specialized Foster Care." Children and Youth Services Review 24 (8): 623-40.

Herman, Daniel B., Ezra S. Susser, and Elmer L. Struening. 1994. "Childhood Out-ofHome Care and Current Depressive Symptoms among Homeless Adults." American Journal of Public Health 84 (11): 1849-51.

Interagency Council on Homelessness. 1994. Priority Home: The Federal Plan to Break the Cycle of Homelessness. Washington, D.C.: U.S. Department of Housing and Urban Development.

Kerman, Benjamin, Judith Wildfire, and Richard P. Barth. 2002. "Outcomes for Young Adults Who Experienced Foster Care." Children and Youth Services Review 24 (5): 319-44.

Koegel, Paul, M. Audrey Burnam, and Sally C. Morton. 1996. "Enumerating Homeless People: Alternative Strategies and Their Consequences." Evaluation Review 20 (4): 378-403.

Koegel, Paul, Elan Melamid, and M. Audrey Burnam. 1995. "Childhood Risk Factors for Homelessness among Homeless Adults." American Journal of Public Health 85 (12): 1642-49.

Lindsey, Elizabeth W., and Fasih U. Ahmed. 1999. "The North Carolina Independent Living Program: A Comparison of Outcomes for Participants and Nonparticipants.” Children and Youth Services Review 21 (5): 389-412.

Mallon, Gerald P. 1998. "After Care, Then Where? Outcomes of an Independent Living Program.” Child Welfare 77 (1): 61-79.

Mangine, Steven J., David Royse, Vernon R. Wiehe, and Michael T. Nietzel. 1990. "Homelessness among Adults Raised as Foster Children: A Survey of Drop-In Center Users." Psychological Reports 67 (3): 739-45.

McDonald, Thomas P., Reva I. Allen, Alex Westerfelt, and Irving Piliavin. 1996. Assessing the Long-Term Effects of Foster Care: A Research Synthesis. Washington, D.C.: CWLA Press.

McMillen, J. Curtis, and Jayne Tucker. 1999. "The Status of Older Adolescents at Exit from Out-of-Home Care." Child Welfare 78 (3): 339-60.

Mech, Edmund V. 1994. "Foster Youths in Transition: Research Perspectives on Preparation for Independent Living." Child Welfare 73 (5): 603-24.

Metraux, Stephen, and Dennis P. Culhane. 1999. "Family Dynamics, Housing, and Recurring Homelessness among Women in New York City Homeless Shelters.” Journal of Family Issues 20 (3): 371-96.

North, Carol S., and Elizabeth M. Smith. 1993. "A Comparison of Homeless Men and Women: Different Populations, Different Needs." Community Mental Health Journal 29 (5): 423-31.

New York City Department of Homeless Services (NYCDHS). 2003. "Homeless Outreach Population Survey Results." NYCDHS, New York. Available online at http://www.nyc. gov/html/dhs/pdf/hopsresults.pdf.

Piliavin, Irving, Michael Sosin, Alex Westerfelt, and Ross L. Matsueda. 1993. "The Duration of Homeless Careers: An Exploratory Study.” Social Service Review 67 (4): 576-98.

Poertner, John, Thomas P. McDonald, and Cyndie Murray. 2000. "Child Welfare Outcomes Revisited." Children and Youth Services Review 22 (9): 789-810.

Roman, Nan P., and Phyllis B. Wolfe. 1997. "The Relationship between Foster Care and Homelessness." Public Welfare 55 (1): 4-9.

Rossi, Peter Henry. 1989. Down and Out in America: The Origins of Homelessness. Chicago: University of Chicago Press.

Stoner, Madeleine R. 1999. "Life after Foster Care: Services and Policies for Former Foster Youth." Journal of Sociology and Social Welfare 26 (4): 159-76.

Susser, Ezra S., Elmer L. Struening, and Sarah Conover. 1987. "Childhood Experiences of Homeless Men.” American Journal of Psychiatry 144 (12): 1599-1601.

U.S. General Accounting Office. 1999. "Foster Care: Effectiveness of Independent Living 
Services Unknown.” Document no. GAO/HEHS-00-13. U.S. General Accounting Office, Washington, D.C.

Wei, L. J., D. Y. Lin, and L. Weissfeld. 1989. "Regression Analysis of Multivariate Incomplete Failure Time Data by Modeling Marginal Distributions." Journal of the American Statistical Association 84 (408): 1065-73.

Whitbeck, Les B., and Ronald L. Simons. 1990. "Life on the Streets: The Victimization of Runaway and Homeless Adolescents." Youth and Society 22 (1): 108-25.

Winkleby, Marilyn A., Beverly Rockhill, Darius Jatulis, and Stephen P. Fortmann. 1992. "The Medical Origins of Homelessness." American Journal of Public Health 82 (10): 1394-98.

Wolch, Jennifer R., Afsaneh Rahimian, and Paul Koegel. 1993. "Daily and Periodic Mobility Patterns of the Urban Homeless." Professional Geographer 45 (2): 159-69.

Zlotnick, Cheryl, Marjorie J. Robertson, and Marguerite A. Wright. 1999. "The Impact of Childhood Foster Care and Other Out-of-Home Placement on Homeless Women and Their Children." Child Abuse and Neglect 23 (11): 1057-68. 